\title{
Woody Plant Root Physiology, Growth, and Development: Introduction to the Colloquium
}

\author{
Eric Young \\ Deportment of Horticultural Science, North Carolina State University, Raleigh, NC 27695
}

The first systematic studies on woody plant root systems were done in the mid-18th Century by Du Hamel Du Monceau, when he excavated tree root systems to determine their size and morphology (Bohm, 1979). In the 19th Century, root research was done primarily by agronomists on field crops, particularly in relation to the use of mineral fertilizers. It was not until the early 1900s that a significant amount of work on woody plant root systems resumed, with root system excavations of forest trees by Krauss et al. (1934) in Germany and fruit trees by Rogers and Vyvyan (1934) in England. Root research in all plants has historically lagged behind research on the shoot, for obvious reasons, and woody plant root research has had the added difficulties inherent in tree research. However, improved techniques in observing, measuring, sampling, and treating root systems both in the field and laboratory have allowed for tremendous development of root research in the past 50 years. This increased effort was exemplified by the organization of the First International Root Symposium held in Leningrad USSR in 1968. Since this symposium, root research has continued to increase at a fast rate. This growth can be represented by the number of references on root physiology retrieved from the computerized literature file BIOSIS. The number of references retrieved using the key words root and physiology, with and without references dealing with agronomic and vegetable crops, is shown in Fig. 1. The second category can be considered as representing woody plant root physiology. It is interesting to note that, from 1968 to 1981, woody plant root research consistently made up $\approx 35 \%$ of the total references. In 1982, it went $>40 \%$, and, in 1987 , it was $50 \%$ of the total. Whether or not this represents a true increase in emphasis on woody plant root research remains to be seen.

Expansion of root research over the past 20 years has led to increased specialization and, to some extent, a divergence of commodity-related areas of research. Root research can be classified into two main fields-root ecology and root physiology. The aim of root ecology is to investigate the influence of environmental factors on the development of plant root systems. Root physiology has as its principal aim the study of physiological processes in roots. However, root ecology and physiology cannot and should not be separated. In every case, root growth and development are con-

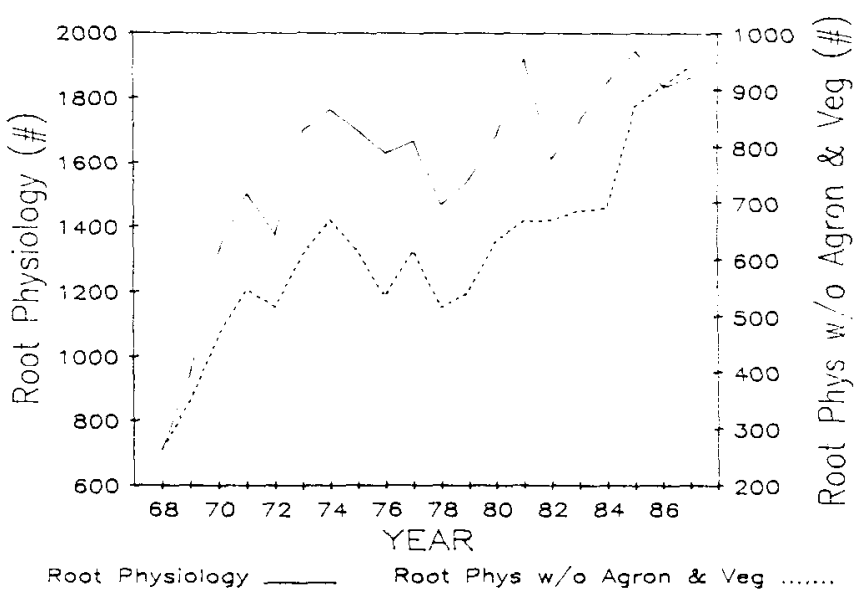

Fig. 1. Number of references retrieved from the computerized literature file BIOSIS that dealt with general root physiology and woody plant root physiology. The key words "root' and "physiology" were used for general root physiology, then nonwoody plant rceferences were deleted using the key words "agronomic", "Gramineae", "monocot", and "vegetable", leaving primarily references on woody plant root physiology. 
trolled by internal factors and physiological processes are governed by external conditions.

Root research has also been separated along commodity lines. Scientists working on agronomic, forest, or horticultural crops traditionally have had little interaction, except through the literature. An obvious overlap in problems and experimental methods exists among forestry, ornamentals, and pomology in studying woody plant root systems. One of the objectives of this colloquium was to increase awareness among these commodity groups of current research in each area.

Plant root research worldwide is currently spread over many different journals and discussed at many different scientific meetings. Only recently have there been efforts to bring together root researchers from different areas; the most far-reaching of which has been the establishment of the International Society of Root Research (ISRR). This society, founded during a symposium held in Austria in 1982, has as its primary aim the increase of communication between scientists working on root research problems. Its membership includes scientists from ecology, ecophysiology, mycology, forestry, agriculture, and horticulture. The first ISRR-sponsored symposium was held in Sweden in 1988.

This colloquium is a small effort to help continue this trend of interdisciplinary exchange between scientists involved in root research. Our contributors include two foresters, two ornamental horticulturists, and a pomologist with a wide range of backgrounds and interests. We believe that these discussions will stimulate further interaction between the groups represented, eventually leading to increased cooperative research that will strengthen our knowledge of woody plant root physiology.

\section{Literature Cited}

Bohm, W. 1979. Methods of studying root systems. Springer-Verlag, New York.

Krauss, G., W. Wobst, G. Gartner. 1934. Humusauflage und Bodennerchwurzelung im Eibenstocker Granitgebiet. Tharandter Forstl. Jahrb. 85:290370.

Rigers, W.S. and M.C. Vyvyan. 1934. Root studies: V. Root stock and soil effect on apple root systems. J. Pomol. Hort. Sci. 12:110-150. 